\title{
Environmental Studies: An Introduction
}

\author{
Matthew N. O. Sadiku1, Tolulope J. Ashaolu², Abayomi Ajayi-Majebi, ${ }^{3}$ and Sarhan M. Musa1
}

${ }_{1}^{1}$ Roy G. Perry College of Engineering, Prairie View A\&M University Prairie View, TX, USA

${ }^{2}$ College of Food Science, Southwest University, Tiansheng Road Beibei District, Chongqing, 400715, P.R. China

${ }^{3}$ Department of Manufacturing Engineering, Central State University, P.O. Box 1004 Wilberforce, OH 45384-1004, USA

E-mail: sadiku@ieee.org; ashaolut@gmail.com; ajayi-majebi@centralstate.edu; smmusa @pvamu.edu

*Corresponding author details: Professor Matthew N.O. Sadiku, sadiku@ieee.org

\begin{abstract}
Environment study deals with the processes in water, air, land, soil, and organisms which cause pollution or degradation of the environment. It is an interdisciplinary approach and its components include biology, geology, chemistry, physics, engineering, sociology, health sciences, anthropology, economics, statistics, and philosophy. It examines the creation, change, and success of environmental policies. The time-sensitive and urgent nature of the environmental changes have created a demand for individuals who possess the skill set for addressing environmental issues. This paper provides an introduction into environmental studies.
\end{abstract}

Keywords: environmental studies; green environment; smart environment; environmental component

\begin{abstract}
INTRODUCTION
The environment sustains life. Man needs to know the importance of environment and help keep the environment as healthy and productive as much as possible. Environmentalists around the world are constantly seeking sustainable solutions to restore a sustainable environment. The environmental crisis is one of the biggest challenges of the $21^{\text {st }}$ century. For this reason, environmental problems are now muchdiscussed around the globe.
\end{abstract}

Environmental problems include [1]: (1) Climate change, which is a change in earth's climate; (2) Rapid urbanization and industrialization have destroyed a substantial part of natural vegetation and forced many wild animals on the verge of extinction; (3) overconsumption which encourages the acquisition of goods in ever increasing amounts; (4) Ozone depletion is the wearing out or reduction of the amount of ozone in the stratosphere; (5) Deforestation is the cutting down of trees and the destruction of natural vegetation; (6) Desertification is land degradation in arid, semi-arid, and dry-sub-humid areas.

Environmental studies refer to a systematic study of human interaction with natural and built environment. It helps us to use natural resources more efficiently and embrace a sustainable way of living. It is a multidisciplinary approach, meaning that it crosses over boundaries of academic disciplines such as biology, geology, politics policy studies, law, geology, religion, engineering, chemistry, and economics to determine humanity's effects on the natural world. Figure 1 illustrates the multidisciplinary nature of environmental studies [2].

Environmental studies is one of the most exciting and fastest growing fields. The purpose of teaching environment studies is to sensitize students towards environmental issues. Students of environmental studies seek to understand environmental problems, offer solutions to them, and find ways to prevent its degradation. They will become environmental problem solver prepared for careers in ecological restoration, pollution control, renewable energy systems, and environmental education, etc. Figure 2 shows some environmental students at work [3].

\section{TYPES OF ENVIRONMENT}

Environment refers to surroundings in which living beings live and non-living things exist. Environment belongs to all the living beings. It plays a major role in the healthy living of human beings. As shown in Figure 3, environment includes air, water, land, living organisms, and materials surrounding us [4].

Since environment is a combination of physical and biological factors, it contains both living and non-living components. Everyone may be affected by environmental issues like global warming, ozone layer depletion, energy resources, acid rain, nuclear accidents, loss of global biodiversity, etc.

- Physical or Living Environment: Environment can be divided into physical or abiotic and living or biotic environment. Physical environment consists of solid, liquid, and gas. These three elements signify lithosphere, hydrosphere, and atmosphere respectively. Living environment consists of plants (flora) and animals (fauna) including human beings. The physical elements of the planet earth, such as terrain, soil, water, climate, flora and fauna formed man's environment.

- Man-made environment: This is when the natural environment is deliberately controlled and converted by mankind. Example include aquariums, cities, community parks, and laboratories.

- Green environment: This refers to the concerns for environmental conservation. This is demonstrated in supporting practices such as conservation practices, investment in renewable energy, and taking actions to 
stop climate change, and reduce carbon footprint. Being environmentally friendly will affect corporate policy and individual behavior. Many individuals cultivate personal gardens and such activity can have direct health benefits. Together, we can leave a greener footprint on the earth for the benefit of the next generation [5].

- Smart environment: The word "smart" means intelligent, while the word "environment" means our surrounding. The term "smart environment" is used differently to refer to smart cities, smart houses, smart classrooms, smart offices, smart factories, smart workplaces, smart rooms, smart health care, and smart laboratories. A smart environment is a physical space where different kinds of smart devices are working together to make inhabitants live more comfortable. It is realized with sensors, actuators, and computational elements, embedded into everyday objects and connected through a network. A smart environment must be able to determine and predict the location of an individual [6].

\section{COMPONENTS OF ENVIRONMENTAL STUDIES}

Environmental studies are a field with wide scope. It is concerned with the issues of sanitation, health, pollution control, biodiversity conservation, solid waste disposal, and conservation of natural resources [1].

- Ecosystem: This is a part of natural environment consisting of a community of living beings and the physical environment. It is the interaction between the living community (plants, animals, and organisms) and the non-living community (soil, air, and water). As shown in Figure 4, the environment consists of the following four segments [1].

$>$ Atmosphere: This refers to the protective blanket of gases, surrounding the earth. It forms a distinctive protective layer about $100 \mathrm{~km}$ thick around the earth.

$>$ Hydrosphere: This comprises all water resources such as ocean, seas, lakes, rivers, glaciers, and ground water.

Lithosphere: This is the outer mantle of the solid earth. It contains minerals occurring in the earth's crust and the soil.

$>$ Biosphere: This constitutes the realm of living organisms and their interactions with the environment (atmosphere, hydrosphere, and lithosphere).

- Natural Resources: These are the resources we obtain from nature or earth. They occur naturally and humans cannot make them. Natural resources can be classified based on their origin, level of development and uses, stock or deposits, and their distribution. Natural resources can be classified as renewable or non-renewable. We also have water resources, mineral resources, land resources, food resources, energy resources, and forest resources.

- Energy Resources: Energy is simply the capacity to do work. Energy appears in several forms. The sun is our primary source of energy. Other sources of energy include water, fossil fuels, petroleum products, and nuclear power plants. Modern lifestyle, industrialization, urbanization, and increase in population have increase global energy requirement. There are two types of energy: renewable energy or non-renewable energy.
Renewable energy (such as hydropower, solar, wind, and geothermal) uses resources that are constantly replaced and are usually less polluting. Non-renewable energy (such as fossil fuels, such as coal, petroleum, and natural gas) cannot be replenished after their depletion.

- Biodiversity: This is also known as "biological diversity." It refers to the existence of number of different species of plants and animals in an environment. Biodiversity is the existence of variability among living organisms on the earth. In view of the degree of threat to biodiversity around the world, there is an urgent need to conserve biodiversity in the world.

- Pollution: This refers to undesirable changes occurring in the physical, chemical, and biological composition of natural environment consisting of air, water, and soil. It is regarded as "an unfavorable alteration" in the sustaining and carrying capacity of the natural environment. Pollution also means the presence of harmful pollutants in an environment that makes this environment unhealthy to live in. There are different types of pollution: air pollution, water pollution, noise pollution, soil or land pollution, marine pollution, thermal pollution, toxic pollution, carcinogenic pollution, and nuclear hazards.

- Solid Waste Management: This refers to collecting, treating, and disposing of solid material that is discarded or is no longer useful. The task of solid waste management presents complex technical challenges. The major sources of solid waste are households, agricultural fields, industries and mining, hotels and catering, roads and railways, hospitals and educational institutions, cultural centers and places of recreation and tourism, etc. Plastic waste is also a solid waste. Solid wastes can be classified as municipal waste, hospital waste, and hazardous waste. The hazardous waste can cause danger to health and environment.

\section{SCOPE OF ENVIRONMENTAL STUDIES}

Environmental studies discipline has multiple scopes which can be summarized as follows [2]:

1. The study creates awareness among the people to know about various renewable and non-renewable resources of the region.

2. It provides the knowledge about ecological systems and cause and effect relationships.

3. It provides necessary information about biodiversity richness and the potential dangers to the species of plants, animals, and microorganisms in the environment.

4. The study enables one to understand the causes and consequences due to natural and human induced disasters (flood, earthquake, landslide, cyclones etc.,) and pollutions and measures to minimize the effects.

5. It enables one to evaluate alternative responses to environmental issues before deciding an alternative course of action.

6. The study enables environmentally literate citizens to make appropriate judgments and decisions for the protection and improvement of the earth.

7. The study exposes the problems of over population, health, hygiene, etc. and the role of arts, science and technology in eliminating or minimizing the evils from the society. 
8. The study tries to identify and develop appropriate and indigenous eco-friendly skills and technologies to various environmental issues.

9. It teaches the citizens the need for sustainable utilization of resources as these resources are inherited from our ancestors to the younger generating without deteriorating their quality.

10. The study enables theoretical knowledge into practice and the multiple uses of environment.

\section{GLOBAL ENVIRONMENTAL STUDIES}

Environmentalists around the world are constantly searching for a sustainable solution to restore a sustainable environment. Environmental studies are offered worldwide through colleges of liberal arts, life science, social science or agriculture. We consider how environmental studies are conducted in some nations.

- United States: Interest in the environment has surged over the past decade. Programs in environmental studies are offered through colleges of liberal arts, life science, or social science. Students in environmental studies gain the intellectual tools they need in order to understand and address the crucial environmental issues of our time. Several associations have been established to promote research and teaching activities in areas related to environmental studies in US. These include [7]:

$>$ Air \& Waste Management Association

$>$ American Water Resources Association

$>$ Association for Environmental Studies and Sciences (AESS)

$>$ Ecological Society of America

> National Association of Environmental Professionals

$>$ National Council for Science and the Environment

$>$ National Parks \& Conservation Association

> National Waste and Recycling Association

$>$ North American Association for Environmental Education

$>$ Society for Conservation Biology

$>$ Soil \& Water Conservation Society

$>$ Water Environment Federation

- India: No other country has probably moved so rapidly from a position of complacency in creating environmental awareness into infusing environmental concepts into academic curriculum. The constitution of India states that it is the duty of the state to "protect and improve the environment and to safeguard the forests and wildlife of the country." To achieve this, a significant number of environmental acts have been enacted in India. These include Wildlife Protection Act of 1972, Water (Prevention and Control of Pollution) Act of 1974, Environmental Protection Act of 1986, Handling and Management of Hazardous Waste Rules in 1989, and the Biological Diversity Act of 2002. Every citizen of India is responsible for protecting and improving the natural environment including forests, lakes, rivers, and wildlife [1]. India is a nation rich in biodiversity which provides different kinds of resources for the people. It forms the basis for biotechnological development.

- Australia: Australia has been experiencing an increasingly high level of recreation and tourism use in its environments. Compared with some overseas countries such as the United Kingdom and the United States, Australia lags behind in undertaking research in this area. Some studies indicate that the most common recreational and tourist activities (such as bush walking, camping, horse-riding) can, if not well managed, adversely affect the values of Australian natural resources. Physical effects include damage to vegetation, track formation, soil loss, and an increase in fire frequency. Littering and water pollution are also seen as impacts associated with bush walking and camping [8].

- Kosovo: This nation, with approximately 2 million people, has undergone severe social and economic disruption. More than 10 years of political crisis and warfare have caused environmental disruption, mass population displacements, and a breakdown of sanitation and hygiene. In January 2000, the Kosovo Institute of Public Health (IPH) in Pristina implemented a new surveillance system for 20 communicable disease syndromes. There are several tularemia syndromes in human, mostly depending on the portal of infection. The outbreak highlighted the need for policies that would lead to improved community water sources and waste management throughout Kosovo. Due of laboratories in Kosovo equipped to work with tularemia, an emergency laboratory was set up to deal with the outbreak samples [9].

\section{CONCLUSION}

Environmental studies help us understand our environment and teaches us to use natural resources more efficiently. There is an ever demanding need for environmental studies because the environment is responsible for making our world beautiful and habitable. With a bachelor's degree in environmental studies, students may pursue careers in education, business, government, political organizations, or private consulting companies. More information about environmental studies can be found in the books in [10-24] and the following related journals:

- Journal of Environmental Studies

- Polish Journal of Environmental Studies

- Bulletin of Environmental Studies

\section{REFERENCES}

[1] "Environmental Studies - Quick guide" https://www.tutorialspoint.com/environmental_studie s/environmental_studies_quick_guide.htm

[2] S. Sarkar, "Introduction to environmental studies," http://www.surendranathcollege.org/new/upload/IND RANIL_KARUNIT\%2012020-05-

16ENVS\%20UNIT\%201\%20Multidisciplinary\%20natur e\%20of\%20Environmental\%20Studies\%20and\%20Sus tainable\%20Development-merged.pdf

[3] "Environmental studies (B.S. or B.A.)"

https://www.niu.edu/academics/undergraduate/envir onmental-studies.shtml 


\section{[4] “Environment," Unknown Source}

[5] M. N. O. Sadiku, O. D. Olaleye, and S. M. Musa," Green Environment," International Journals of Advanced Research in Computer Science and Software Engineering, vol. 9, no. 6, June 2019, pp. 51-54.

[6] M. N. O. Sadiku, S. M. Musa, and A. Ajayi-Majebi, "Smart environment: A primer," International Journal of Environmental and Ecology Research, vol. 1, no. 1, January 2019, pp. 25-26.

[7] “Career and post-graduate development," Unknown Source.

[8] D. Sun and D. Walsh, "Review of studies on environmental impacts of recreation and tourism in Australia," Journal of Environmental Management, vol. 54, no. 4, August 1998, pp. 323-338.

[9] R. Reintjes, "Tularemia outbreak investigation in Kosovo: Case control and environmental studies," Emerging Infectious Diseases, vol. 8, no. 1, January 2002, pp. 69-73.

[10] G. Ibarra-Berastegi, C.A. Brebbia, and P. Zannetti (eds.), Development and Application of Computer Techniques to Environmental Studies VIII. WIT Press, 2000.

[11] M. Basu and X. Savarimuthu, Fundamentals of Environmental Studies. Cambridge University Press, 2015.

[12] D. A. Kopec, Environmental Psychology for Design. New York, Bloomsbury Publishing, 2018.

[13] R. W. Casteel, Fish Remains in Archaeology and Paleo-Environmental Studies.

New York: Harcourt Brace Jovanovich: Academic Press, 1976.

[14] N. Castree, M. Hulme, and J. D. Proctor (eds.), Companion to Environmental Studies. Rouledge, 2018.

[15] W. W. Wang, J. W. Gorsuch, and J. S. Hughes (eds.), Plants for Environmental Studies. Boca Raton, FL: CRC Press, 2020.

[16] I. Linkov and E. Moberg, Multi-Criteria Decision Analysis: Environmental Applications and Case Studies. Boca Raton, FL: CRC Press, 2011.

[17] E. Bharucha, Environmental Studies: For Undergraduate Courses of all Branches of Higher Education. New Delhi, University Grants Commission, 2004.

[18] S. Kumar, Fundamentals of Environmental Studies for Undergraduate Courses: A Textbook Based on Syllabus Prescribed by University Grants Commission (UGC). Sultan Chand \& Sons, 2018.
[19] M. Ruth (ed.), Handbook of Research Methods and Applications in Environmental Studies. Edward Elgar Publishing, 2015.

[20] J. Adamson, W. A. Gleason, and D. N. Pellow (eds.), Keywords for Environmental Studies. New York: New York University Press, 2016.

[21] K. Abe, N. Daniel, and Mallee, Global Environmental Studies. Springer, 2020.

[22] A. Kaushik, Perspectives in Environmental Studies. New Age International Publishers, 2014.

[23] R. W. Li (ed.), Metagenomics and Its Applications in Agriculture, Biomedicine and Environmental Studies. Nova Science Publishers, 2011.

[24] R. Rajagopalan, Environmental Studies: From Crisis to Cure. Oxford University Press; 3rd edition, 2016.

\section{ABOUT AUTHORS}

Matthew N.0. Sadiku is a professor emeritus in the Department of Electrical and Computer Engineering at Prairie View A\&M University, Prairie View, Texas. He is the author of several books and papers. His areas of research interests include computational electromagnetics and computer networks. He is a fellow of IEEE.

Tolulope J. Ashaolu works at Southwest University, P.R.C. He is the author of several papers and a book. His research interests include functional foods and food microbiology.

Abayomi Ajayi-Majebi is a professor in the Department of Manufacturing Engineering at Central State University in Wilberforce, Ohio. In 2015 he was honored by the White House as a Champion of Change for his significant contributions to the engineering education of minority students. He is a senior member of both the Society of Manufacturing Engineers and the American Society for Quality.

Sarhan M. Musa is a professor in the Department of Electrical and Computer Engineering at Prairie View A\&M University, Prairie View, Texas. He has been the director of Prairie View Networking Academy, Texas, since 2004. He is an LTD Sprint and Boeing Welliver Fellow. His areas of research interests include computational electromagnetics and computer networks. 


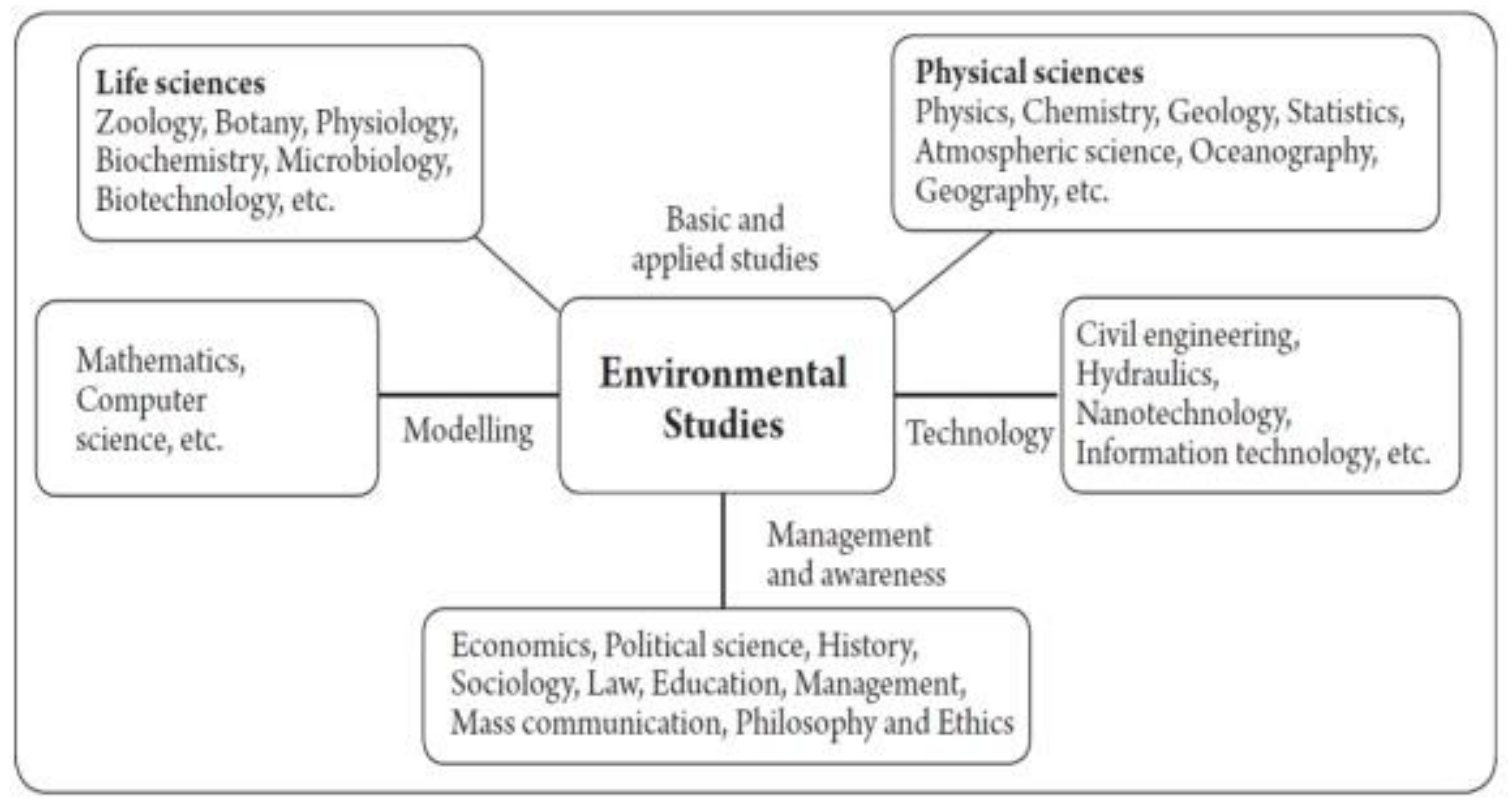

FIGURE 1: MULTIDISCIPLINARY NATURE OF ENVIRONMENTAL STUDIES [2].

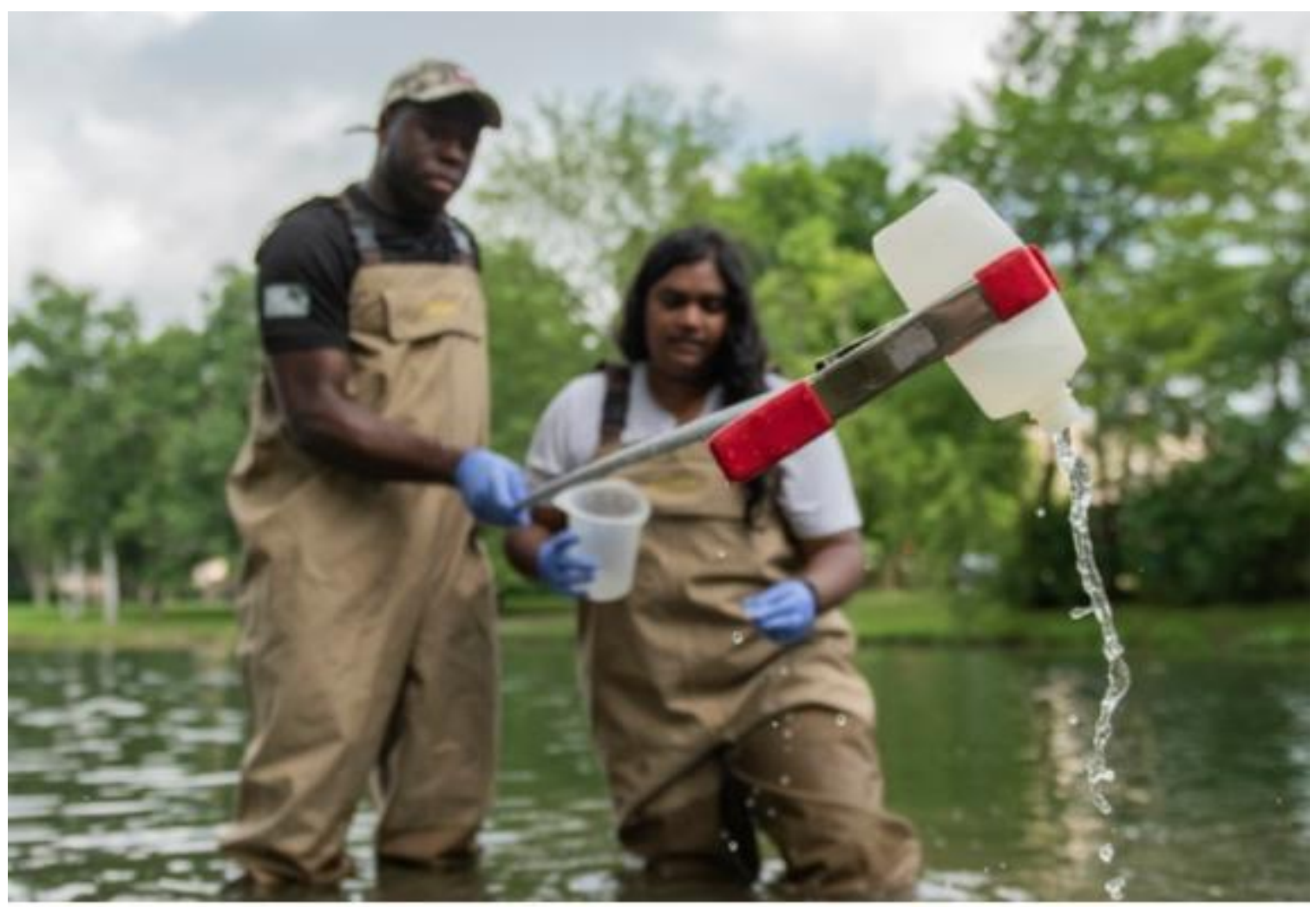

FIGURE 2: ENVIRONMENTAL STUDENTS AT WORK [3]. 


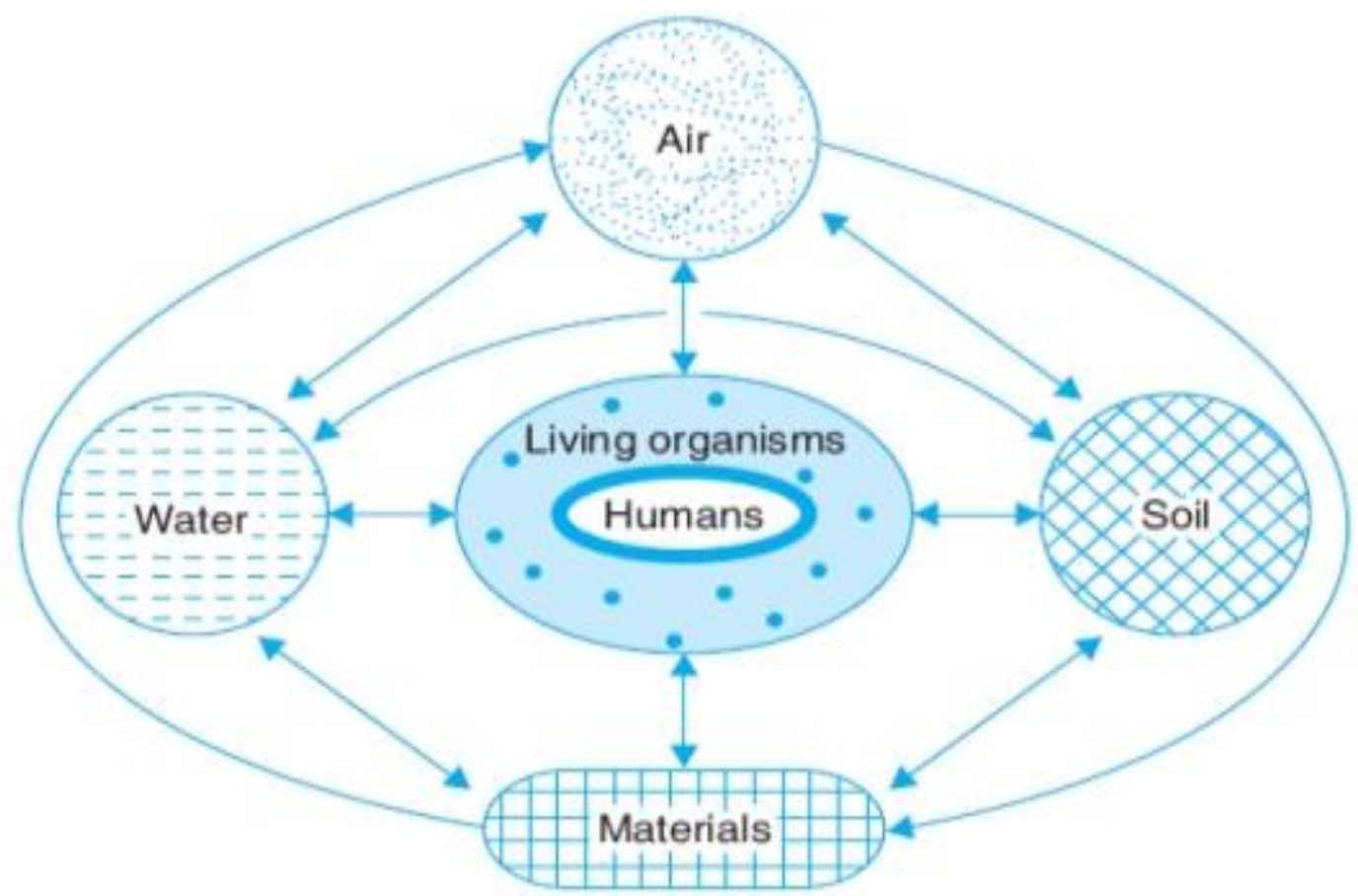

FIGURE 3: THE CONCEPT OF ENVIRONMENT [4].

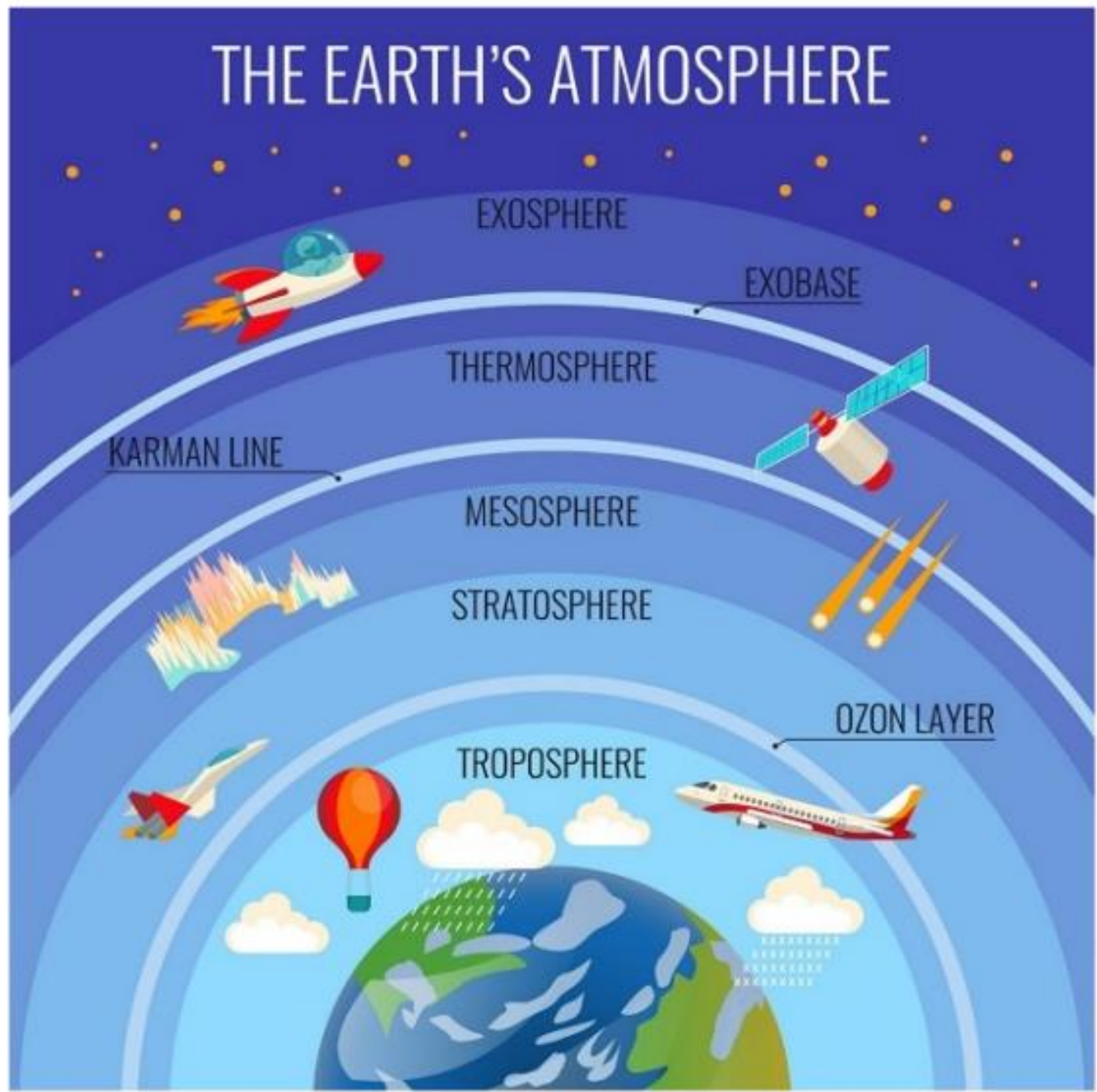

FIGURE 4: SEGMENTS OF THE ENVIRONMENT [1]. 